\title{
Arginyl-tRNA Synthetase Facilitates Complex Formation Between Seryl-tRNA Synthetase and its Cognate Transfer RNA ${ }^{\dagger}$
}

\author{
Vlatka Godinić-Mikulčić, ${ }^{*}$ Jelena Jarić, and Ivana Weygand-Đurašević \\ University of Zagreb, Faculty of Science, Department of Chemistry, Horvatovac 102a, HR-10000 Zagreb, Croatia
}

RECEIVED JULY 17, 2012; REVISED SEPTEMBER 30, 2012; ACCEPTED OCTOBER 3, 2012

\begin{abstract}
Several studies have revealed the involvement of multi aminoacyl-tRNA synthetase complexes (MSC) in archaeal and eukaryotic translation. Here we analyzed interactions of atypical Methanothermobacter thermautotrophicus seryl-tRNA synthetase (MtSerRS), transfer RNA (tRNA ${ }^{\text {Ser }}$ ) and arginyl-tRNA synthetase (ArgRS). Surface plasmon resonance (SPR) was used to determine dissociation constants for the MtSerRS:tRNA ${ }^{\text {Ser }}$ complex and the results were consistent with cooperative binding of tRNA $^{\text {Ser }}$. This finding was supported by the ability of MtSerRS to bind two tRNAs in gel mobility shift assay. Notably, the MtSerRS:tRNA ${ }^{\text {Ser }}$ complex formation was stimulated by MtArgRS, previously determined interacting partner of MtSerRS. MtArgRS decreases $K_{\mathrm{d}}$ for MtSerRS:tRNA ${ }^{\text {Ser }}$ two-fold, but does not affect cooperative properties or stoichiometry of the complex. Further investigation of complex formation between MtSerRS and tRNA ${ }^{\text {Ser }}$ showed that this molecular interaction is salt-dependent. The most pronounced improvements in binding were determined at high ionic strength, using Tris as a buffering agent, while the addition of $\mathrm{Mg}^{2+}$ ions led to the same SPR response. (doi: 10.5562/cca2146)
\end{abstract}

Keywords: aminoacyl-tRNA synthetase, seryl-tRNA synthetase, arginyl-tRNA synthetase, tRNA, surface plasmon resonance

\section{INTRODUCTION}

The successful completion of gene expression is dependent on efficient and accurate translation of mRNAs to synthesize proteins, catalyzed by the ribosome. ${ }^{1}$ The fidelity of protein synthesis relies on precise mRNA:tRNA decoding interactions, and the highly specific attachment of amino acids (aa) to tRNAs during aminoacyl-tRNA synthesis. ${ }^{2}$ The later process is catalyzed by the aminoacyl-tRNA synthetases (aaRSs). ${ }^{3}$ Recent evidences ${ }^{4,5}$ revealed that these housekeeping enzymes tend to form macromolecular complexes in all three domains of life. ${ }^{5}$ Such associations may influence the efficiency and the accuracy of aminoacyl-tRNA formation. In this context, we previously explored the ability of seryl-tRNA synthetases (SerRSs), which catalyze esterification of cognate $\mathrm{tRNA}{ }^{\mathrm{Ser}}$ isoacceptors with serine, to interact with other aaRSs and with nonsynthetase proteins. ${ }^{6}$ Although, generally, the aaRSs that recognize the same amino acid are rather conserved in terms of sequences and 3D-structures in all domains of life, the two diverged types of SerRSs exist. ${ }^{7-10} \mathrm{Bac}-$ terial-type SerRSs function in a variety of archaeal, bacterial and eukaryotic organisms, while somewhat atypical, methanogenic-type SerRS was found only in methanogenic archaea, ${ }^{10,11}$ the organisms which often inhabit the environments characterized by extreme living conditions (anaerobic, thermofilic, psychrophilic, halophilic). We have recently shown that methanogenictype SerRSs display several idiosyncratic structural features in comparison with bacterial-type SerRSs. ${ }^{11-13}$ Although all SerRSs are functional homodimers with a C-terminal active site domain typical for class II aaRSs and an N-terminal domain that is responsible for tRNA binding, ${ }^{10,14}$ the representatives of the two SerRS types exhibit different modes of substrate recognition, based on structurally different tRNA binding domains $\mathrm{s}^{11-13}$ and the presence of catalytic zinc ion in the active site of methanogenic-type SerRS. Both types of enzymes bind one or two cognate tRNAs across two protein subunits, ${ }^{12,15}$ and it seems that in both systems tRNA binding is enhanced by the interaction of SerRSs with other proteins. ${ }^{6,16}$ We have previously shown that yeast SerRS (a bacterial-type enzyme) associates with peroxin Pex $21 p,{ }^{16}$ while SerRSs from methanogens form assemblies with arginyl-tRNA synthetase (ArgRS). ${ }^{6}$ In this paper we present further evidence that interaction of MtSerRS and RNAA $^{\text {Ser }}$ is salt-dependent and that ArgRS from

\footnotetext{
$\dagger$ This article belongs to the Special Issue devoted to the $85^{\text {th }}$ anniversary of Croatica Chemica Acta.

* Author to whom correspondence should be addressed. (E-mail: vgodinic@chem.pmf.hr)
} 
Methanothermobacter thermautotrophicus (MtArgRS) facilitates binding of tRNA ${ }^{\text {Ser }}$. Thus, such aaRSs complexes may be especially important under extreme environmental conditions due to diverse habitats such as geothermal, marine hydrothermal springs, rivers and sea sediments, the digestive system of animals and the anaerobic accumulation of waste. MtSerRS:ArgRS association presumably constitutes a part of thermo- ${ }^{6}$ and osmoadaptation mechanisms of thermophilic methanogenic archaea, by providing an optimal microenvironment for efficient seryl-tRNA synthesis.

\section{EXPERIMENTAL}

\section{Preparation of Proteins and tRNA}

Preparation of recombinant His $_{6}$-MtSerRS or GSTMtArgRS was done by transforming E. coli BL21(DE3) (Stratagene) with pET28 or pGEX-6P-2 vectors containing the relevant inserts and growing the resulting strains on LB media supplemented with ampicillin or kanamycin as described. ${ }^{6}$ Protein concentration was determined by active site titration and Methanosarcina barkeri tRNA $_{\text {GGA }}^{\text {Ser }}$ (MbtRNA ${ }_{\text {GGA }}$ ) was produced in vivo as previously described. ${ }^{12}$

\section{Gel Mobility Shift Assay}

To check for complex formation between tRNA and

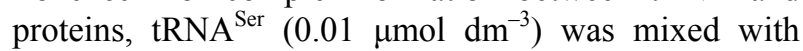
varying concentrations of MtSerRS dimer (0.005-0.4 $\left.\mu \mathrm{mol} \mathrm{dm}{ }^{-3}\right)$, GST-MtArgRS $\left(0.005-0.4 \mu \mathrm{mol} \mathrm{dm}{ }^{-3}\right)$, or BSA (New England Biolabs) $\left(0.005-0.4 \mu \mathrm{mol} \mathrm{dm}{ }^{-3}\right.$ ) and incubated for $15 \mathrm{~min}$ at temperature of $37{ }^{\circ} \mathrm{C}$ in 20 mmol dm ${ }^{-3}$ TrisHCl $(\mathrm{pH}=7.0), 50 \mathrm{mmol} \mathrm{dm}^{-3} \mathrm{NaCl}$ and $6 \mathrm{mmol} \mathrm{dm}^{-3} \mathrm{MgCl}_{2}$. The experiment was performed at a concentration of $\mathrm{tRNA}^{\mathrm{Ser}}$ which is much lower than the dissociation constants of the MtSerRS:tRNA ${ }^{\mathrm{Ser}}$. Under these conditions, tRNA binds to a very small proportion of the MtSerRS in the reaction mixture and has an insignificant effect on a concentration of free MtSerRS. On the other hand, for stoichiometric titration

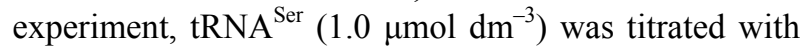

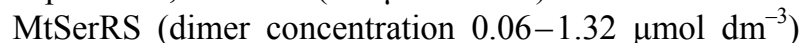
using $0.06-1.32 \mu \mathrm{mol} \mathrm{dm} \mathrm{dm}^{-3}$ MtArgRS or BSA in the reaction. For each protein concentration, fractional saturation was calculated for three trials. The binding stoichiometry of MtSerRS:tRNA ${ }^{\text {Ser }}$ complex was determined from the concentration of protein required to saturate binding to a fixed concentration of tRNA. The concentration of the fixed component was 50-fold greater than the $K_{\mathrm{d}, \mathrm{av}}$ to permit direct stoichiometric titration. Samples were subjected to electrophoresis on a polyacrylamide native gel $(w=12 \%)$ in electrophoretic buffer $\left(25 \mathrm{mmol} \mathrm{\textrm {dm } ^ { - 3 }} \mathrm{Mes}, 25 \mathrm{mmol} \mathrm{dm}{ }^{-3}\right.$
TrisHCl $(\mathrm{pH}=7.6))$. Electrophoresis was performed at temperature of $4{ }^{\circ} \mathrm{C}$ for $3 \mathrm{~h}$ at $120 \mathrm{~V}$, and gels were stained with silver, Toluidine Blue or Coomassie Blue.

\section{Surface Plasmon Resonance}

Kinetic studies were performed at temperature of $20{ }^{\circ} \mathrm{C}$ using a BIACORE T100 surface plasmon resonance (SPR) instrument (Biacore Inc., Uppsala Sweden) at FGCZ (Functional Genomic Center Zürich). MtSerRS was covalently attached to a carboxymethyl dextrancoated gold surface (CM5 sensor chip, Biacore Inc., Uppsala). The carboxymethyl groups of dextran were activated with injection of a mixture of 1-ethyl-3(3-dimethylaminopropyl)-carbodiimide hydrochloride and $\mathrm{N}$-hydroxysuccinimide. Seryl-tRNA synthetase was attached to the surface at $\mathrm{pH}=5.0 \mathrm{in} 10 \mathrm{mmol} \mathrm{dm}^{-3}$ sodium acetate. Protein was immobilized at levels of 800 response units in one flow cell. The kinetics of association and dissociation were monitored at a flow rate of 30

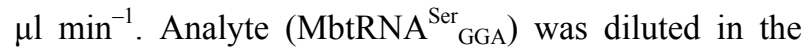
running buffer $\left(20 \mathrm{mmol} \mathrm{dm}^{-3}\right.$ TrisHCl $(\mathrm{pH}=7.5), 100$ $\mathrm{mmol} \mathrm{dm}{ }^{-3} \mathrm{NaCl}, 6 \mathrm{mmol} \mathrm{dm}{ }^{-3} \mathrm{MgCl}_{2}$ and $5 \mathrm{mmol} \mathrm{dm}$ ${ }^{3}$ DTT). Binding was monitored at concentration range of $4.9 \mathrm{nmol} \mathrm{dm}^{-3}-1.25 \mu \mathrm{mol} \mathrm{dm}{ }^{-3}$ tRNA $^{\mathrm{Ser}}$. After the end of each injection, tRNA was allowed to dissociate. Data reported are the differences in SPR signal between the flow cell containing MtSerRS and the reference cell without enzyme immobilized. Duplicate injections were made for each protein concentration in one round of measurement and each experiment was repeated twice. The data were analyzed with Biacore T100 Evaluation Software using the Heterogeneous analyte model (model 1) for parallel reactions which allows quantitative binding analysis of two analytes to the ligand; in our case two tRNAs to MtSerRS.

Model 1: Heterogeneous analyte

$$
\begin{aligned}
& \mathrm{A}+\mathrm{B} \underset{k_{\mathrm{d} 1}}{\stackrel{k_{\mathrm{a} 1}}{\rightleftharpoons}} \mathrm{AB} \\
& \mathrm{A}+\mathrm{AB} \underset{k_{\mathrm{d} 2}}{\stackrel{k_{\mathrm{a} 2}}{\rightleftharpoons}} \mathrm{A}_{2} \mathrm{~B}
\end{aligned}
$$

, where $K_{\mathrm{a} 1}=\left(k_{\mathrm{a} 1} / k_{\mathrm{d} 1}\right) ; K_{\mathrm{a} 2}\left(k_{\mathrm{a} 2} / k_{\mathrm{d} 2}\right)$; and $K_{\mathrm{d} 1}=1 / K_{\mathrm{a} 1}, K_{\mathrm{d} 2}=$ $1 / K_{\mathrm{a} 2}$

The buffer compositions for ranking experiment were as follows: $A$ : $20 \mathrm{mmol} \mathrm{\textrm {dm } ^ { - 3 }}$ TrisHCl $(\mathrm{pH}=7.5)$, $50 \mathrm{mmol} \mathrm{dm}^{-3}$ ammonium acetate, $6 \mathrm{mmol} \mathrm{dm}{ }^{-3} \mathrm{MgCl}_{2}$, $5 \mathrm{mmol} \mathrm{dm}{ }^{-3}$ DTT; $B: 20 \mathrm{mmol} \mathrm{dm}{ }^{-3}$ TrisHCl $(\mathrm{pH}=$ 7.5), $100 \mathrm{mmol} \mathrm{dm}{ }^{-3} \mathrm{NaCl}, 6 \mathrm{mmol} \mathrm{dm} \mathrm{MgCl}_{2}$, $5 \mathrm{mmol} \mathrm{dm}{ }^{-3}$ DTT; $C: 20 \mathrm{mmol} \mathrm{dm}{ }^{-3}$ TrisHCl $(\mathrm{pH}=$ 7.5), $6 \mathrm{mmol} \mathrm{dm} \mathrm{MgCl}_{2}, 5 \mathrm{mmol} \mathrm{dm}{ }^{-3}$ DTT; $D$ : $20 \mathrm{mmol} \mathrm{dm}^{-3}$ TrisHCl $(\mathrm{pH}=8.0), 50 \mathrm{mmol} \mathrm{dm}^{-3}$ 
(a)

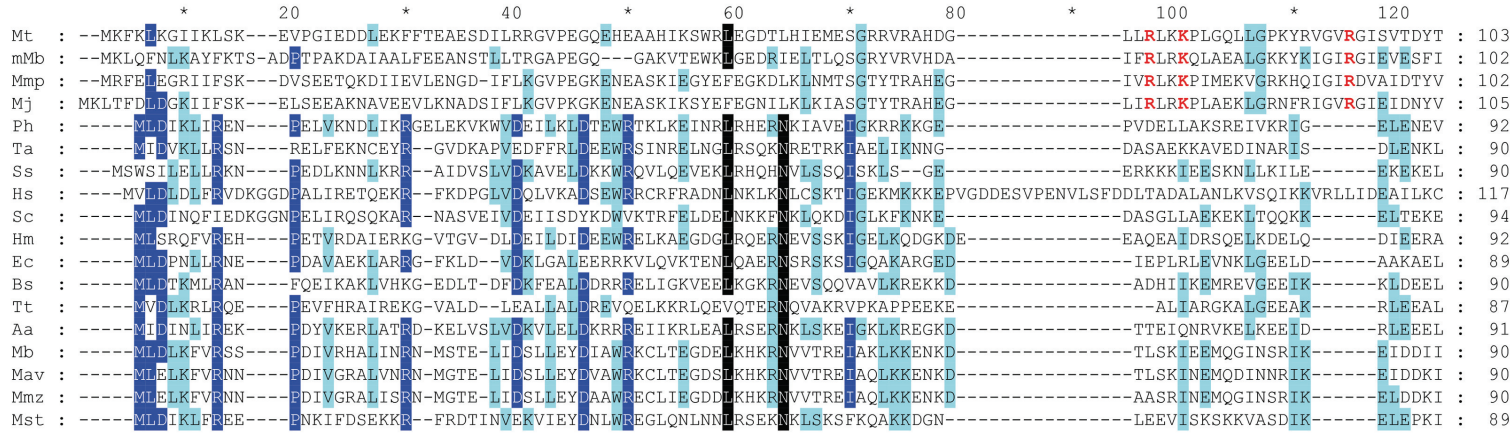

(b)

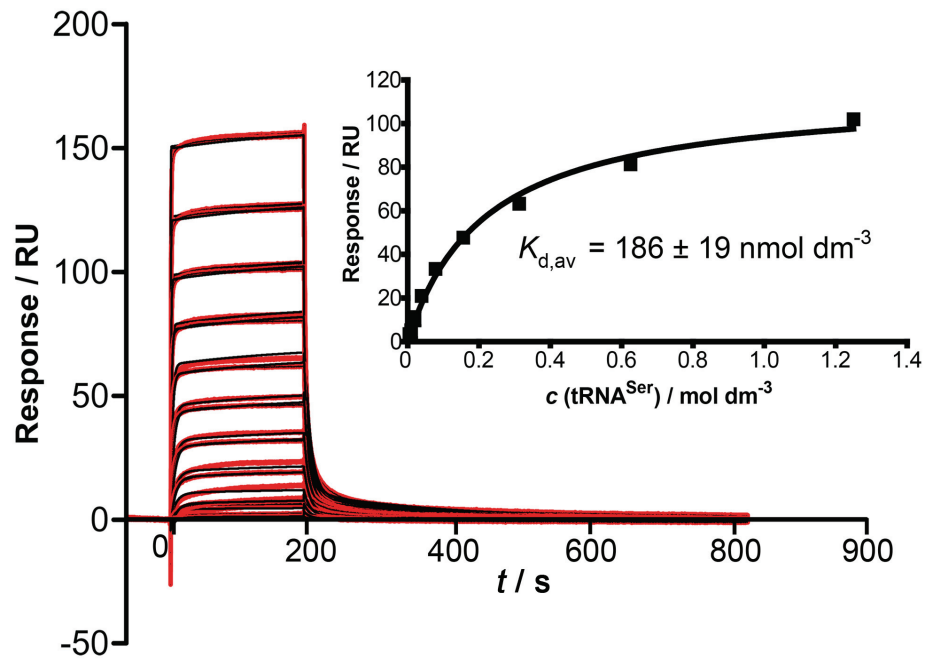

Figure 1. Multiple sequence alignment of N-terminal domains from SerRSs from different organisms. Amino acid sequences were aligned using the software ClustalW (http://www.ebi.ac.uk/Tools/msa/clustalw2/). According to the percentage of conservation, $80 \%$ conserved amino acids are shaded as black, $60 \%$ conserved as blue and $40 \%$ conserved as light-blue. Abbreviations for names of organisms are the following: Mt (Methanothermobacter thermautotrophicus), mMb (methanogenic-type SerRS from Methanosarcina barkeri), Mmp (Mathanococcus maripaludis), Mj (Methanocaldococcus jannashii), $\mathrm{Ph}$ (Pyrococcus horikoshii), Ta (Thermoplasma acidophilum), Ss (Sulfolobus sulfatarius), Hs (Homo sapiens), Sc (Saccharomyces cerevisiae), Hm (Haloarcula marismortui), Ec (Escherichia coli), Bs (Bacillus sulfolobus), Tt (Thermus thermophilus), Aa (Aquifex aeolicus), Mb (bacterial-type SerRS from Methanosarcina barkeri), Ma (Methanosarcina acetivorans), Mmz (Methanosarcina mazei) and Mst (Methanosarcina stadmanae). Amino acids of metanogenic-type SerRS important for tRNA recogniton are marked in red (a).

Kinetic analysis of MbtRNA ${ }^{\text {Ser }}$ binding to immobilized MtSerRS monitored by a surface plasmon resonance. Sensorgrams (red) were obtained for the binding of different concentrations of MbtRNA ${ }^{\mathrm{Ser}}\left(4.9 \mathrm{nmol} \mathrm{dm}^{-3}-1.25 \mu \mathrm{mol} \mathrm{dm}^{-3}\right)$ to MtSerRS in $20 \mathrm{mmol}$ $\mathrm{dm}^{-3}$ TrisHCl $(\mathrm{pH}=7.5), 100 \mathrm{mmol} \mathrm{dm}^{-3} \mathrm{NaCl}, 6 \mathrm{mmol} \mathrm{dm}^{-3} \mathrm{MgCl}_{2}$ and $5 \mathrm{mmol} \mathrm{dm}{ }^{-3}$ DTT. Data were fit to the Heterogeneous analyte model (black). Inset: The experimental curves were evaluated by Steady State Affinity model as well and average dissociation constant $K_{\mathrm{d}, \mathrm{av}}=186 \pm 19 \mathrm{nmol} \mathrm{dm}^{-3}$ was defined (b).

ammonium acetate, $6 \mathrm{mmol} \mathrm{dm} \mathrm{mgCl}_{2}, 5 \mathrm{mmol}$ $\mathrm{dm}^{-3}$ DTT; $E$ : $10 \mathrm{mmol} \mathrm{dm}{ }^{-3}$ HepesKOH $(\mathrm{pH}=7.4)$, $150 \mathrm{mmol} \mathrm{dm}{ }^{-3} \mathrm{NaCl}, 3 \mathrm{mmol} \mathrm{dm}{ }^{-3}$ EDTA, Np40 $(\varphi=$ $0.00005 \%) ; F: 20 \mathrm{mmol} \mathrm{dm}{ }^{-3}$ TrisHCl (pH = 7.5), 200 mmol dm ${ }^{-3} \mathrm{NaCl} ; 5 \mathrm{mmol} \mathrm{dm}{ }^{-3} \mathrm{DTT}$; $G: 20 \mathrm{mmol} \mathrm{dm}^{-3}$ TrisHCl (pH = 7.5), $100 \mathrm{mmol} \mathrm{dm}^{-3} \mathrm{NaCl}, 5 \mathrm{mmol} \mathrm{dm}^{-3}$ DTT; $H$ : $20 \mathrm{mmol} \mathrm{dm}^{-3}$ TrisHCl $(\mathrm{pH}=8.0), 150 \mathrm{mmol}$ $\mathrm{dm}^{-3} \mathrm{NaCl}, 6 \mathrm{mmol} \mathrm{dm}{ }^{-3} \mathrm{MgCl}_{2}, 5 \mathrm{mmol} \mathrm{dm}{ }^{-3}$ DTT; $I$ : $20 \mathrm{mmol} \mathrm{dm}^{-3}$ TrisHCl $(\mathrm{pH}=7.5), 100 \mathrm{mmol} \mathrm{dm}^{-3}$ $\mathrm{NaCl}, 6 \mathrm{mmol} \mathrm{dm}{ }^{-3} \mathrm{MgCl}_{2}, 5 \mathrm{mmol} \mathrm{dm}{ }^{-3}$ DTT, $3 \mathrm{mmol}$ $\mathrm{dm}^{-3}$ ATP; $J: 10 \mathrm{mmol} \mathrm{dm}^{-3}$ Hepes $(\mathrm{pH}=7.4), 50 \mathrm{mmol}$ $\mathrm{dm}^{-3} \mathrm{NaCl}, 6 \mathrm{mmol} \mathrm{dm} \mathrm{MgCl}_{2}, 5 \mathrm{mmol} \mathrm{dm}{ }^{-3}$ DTT.

\section{RESULTS AND DISCUSSION}

\section{Determination of Kinetic Parameters for MtSerRS:tRNA ${ }^{\text {Ser }}$ Interaction by Surface Plasmon Resonance}

Seryl-tRNA synthetase from methanogenic archaeon Methanosarcina barkeri, contains an idiosyncratic Nterminal domain, composed of an antiparallel beta-sheet capped by a helical bundle, connected to the catalytic core by a short linker peptide. ${ }^{11}$ Based on the structural information and the docking model, we have previously mutated various positions within the $\mathrm{N}$-terminal region 
Table 1. Kinetic parameters determined by SPR for MtSerRS:tRNA ${ }^{\text {Ser }}$ interaction in agreement with the Heterogeneous analyte model. $C h i^{2}=3.85$ and denotes statistical value that describes the accuracy of matching the experimental data with the chosen model of binding. The values $<10$ are acceptable $^{35}$

\begin{tabular}{ll}
\hline Kinetic parameters & \\
\hline$k_{\mathrm{a} 1} / \mathrm{mol}^{-1} \mathrm{dm}^{3} \mathrm{~s}^{-1}$ & $3430 \pm 15$ \\
$k_{\mathrm{d} 1} / \mathrm{s}^{-1}$ & $0.00499 \pm 1 \times 10^{-5}$ \\
$k_{\mathrm{a} 2} / \mathrm{mol}^{-1} \mathrm{dm}^{3} \mathrm{~s}^{-1}$ & $1.189 \times 10^{6} \pm 3.3 \times 10^{3}$ \\
$k_{\mathrm{d} 2} / \mathrm{s}^{-1}$ & $0.1735 \pm 5 \times 10^{-4}$ \\
$K_{\mathrm{d} 1} / \mu \mathrm{mol} \mathrm{dm}^{-3}$ & 1.455 \\
$K_{\mathrm{a} 1} / \mathrm{mol}^{-1} \mathrm{dm}^{3}$ & $6.873 \times 10^{5}$ \\
$K_{\mathrm{d} 2} / \mu \mathrm{mol} \mathrm{dm}^{-3}$ & 0.1459 \\
$K_{\mathrm{a} 2} / \mathrm{mol}^{-1} \mathrm{dm}^{3}$ & $6.853 \times 10^{6}$ \\
\hline
\end{tabular}

of $M$. barkeri SerRS and probed their involvement in tRNA binding. ${ }^{13}$ The results obtained by $\mathrm{SPR}^{13}$ revealed that residues Arg76, Lys79 and Arg94 have pronounced effect on SerRS:tRNA ${ }^{\text {Ser }}$ complex formation and the dissociation constants $\left(K_{\mathrm{d}}\right)$ in comparison with the wild type SerRS:tRNA ${ }^{\text {Ser }}$ interaction. These amino acids are conserved in the primary structure of MtSerRS (corresponding to amino acids Arg77, Lys80 and Arg95) (Figure 1a) and in several other methanogenic-type SerRSs. According to the sequence alignments, ${ }^{11}$ MtSerRS also possesses other features characteristic for methanogenic-type SerRS enzymes, that is a shorter motif II, an insertion at the position of 401-417 and a unique insertion of 30 amino acids (at positions 273305) between motifs I and II, which adopts helix-turnhelix (HTH) structure. Furthermore, tRNA ${ }^{\text {Ser }}$ isoacceptors from $M$. barkeri and $M$. thermautotrophicus are strikingly similar: the nucleotide pair G30:C40 is present in all serine tRNAs, all possess characteristic long variable arm, discriminatory base G73, nucleotide pair G1:C72 and one unpaired nucleotide at position $48 .{ }^{17}$ Observed structural resemblance in proteins and tRNAs strengthened the assumption about heterologous recognition between MtSerRS and MbtRNA $^{\text {Ser }}$. As expected, MtSerRS binds M. barkeri tRNA $^{\text {Ser }}$ with rather high affinity (Figure $1 b$ ).

The kinetic parameters for binding MtSerRS and tRNA $^{\text {Ser }}$ were determined using surface plasmon resonance (Figure $1 \mathrm{~b}$ and Table 1) in agreement with the Heterogeneous analyte binding model (model 1). In this model, one tRNA (A) binds to the ligand B (MtSerRS) to form a complex AB. The second tRNA (A) binds to the $\mathrm{AB}$ complex and forms a complex $\mathrm{A}_{2} \mathrm{~B}$. The sensorgram in this model reflects the sum of the two binding reactions and the equilibrium constant for the second step $\left(K_{\mathrm{a} 2}=6.853 \times 10^{6} \mathrm{~mol}^{-1} \mathrm{dm}^{3}\right)$ is higher than that for the first step $\left(K_{\mathrm{a} 1}=6.873 \times 10^{5} \mathrm{~mol}^{-1} \mathrm{dm}^{3}\right)$ showing the cooperative binding of tRNA ${ }^{\text {Ser }}$ (Table 1). The first step of binding one tRNA which involves formation of a bimolecular complex between tRNA ${ }^{\text {Ser }}$ and the flexibly exposed N-terminal domain of SerRS $\left(K_{\mathrm{d} 1}=1.455 \mu \mathrm{mol}\right.$ $\mathrm{dm}^{-3}$, Table 1) changes the affinity for the second tRNA $\left(K_{\mathrm{d} 2}=0.1459 \mu \mathrm{mol} \mathrm{dm}{ }^{-3}\right.$, Table 1$)$.

Table 2. Buffer solution composition and ionic strength. We refer to complete solution $(A-J)$ simply as the buffer. The concentrations of buffer species $\left(\mathrm{Na}^{+}, \mathrm{Cl}^{-}, \mathrm{Mg}^{2+}, \mathrm{NH}^{4+}, \mathrm{CH}_{3} \mathrm{COO}^{-}\right)$were calculated based on published $\mathrm{pK}_{a} \mathrm{~s}$ and the HendersonHasselbach equation ${ }^{36}$

\begin{tabular}{|c|c|c|c|c|c|c|c|c|c|c|c|c|}
\hline Buffer $^{(a),(b)}$ & $c$ & $\mathrm{Na}^{+}$ & $\mathrm{Cl}^{-}$ & $\mathrm{Mg}^{2+}$ & $\mathrm{NH}^{4+}$ & $\mathrm{CH}_{3} \mathrm{COO}^{-}$ & $\mathrm{B}^{+}$ & $\mathrm{B}$ & $\mathrm{B}^{-}$ & $\mathrm{N}^{+}$ & $I_{c}$ & $R_{\max }$ \\
\hline$F$ & 20 & 200 & 217 & - & - & - & 17 & 3 & - & 17 & 217 & 120 \\
\hline$H$ & 20 & 150 & 175 & 6 & - & - & 13 & 7 & - & 13 & 181 & 72 \\
\hline$G$ & 20 & 100 & 117 & - & - & - & 17 & 3 & - & 17 & 117 & 69 \\
\hline$I$ & 20 & 100 & 129 & 6 & - & - & 17 & 3 & - & 17 & 159 & 66 \\
\hline$A$ & 20 & - & 29 & 6 & 50 & 50 & 17 & 3 & - & 17 & 83 & 65 \\
\hline$B$ & 20 & 100 & 129 & 6 & - & - & 17 & 3 & - & 17 & 135 & 65 \\
\hline$D$ & 20 & - & 25 & 6 & 50 & 50 & 13 & 7 & - & 13 & 81 & 55 \\
\hline$C$ & 20 & - & 29 & 6 & - & - & 17 & 3 & - & 17 & 35 & 35 \\
\hline$J_{H}$ & 10 & 54 & 62 & 6 & - & - & - & 6 & 4 & 6 & 72 & 34 \\
\hline$E_{H}$ & 10 & 154 & 150 & - & - & - & - & 6 & 4 & 6 & 168 & 30 \\
\hline
\end{tabular}

(a) All concentrations are expressed in $\mathrm{mmol} \mathrm{dm}^{-3}$.

(b) $\mathrm{B}^{+}$, positively charged buffer; $\mathrm{B}^{-}$, negatively charged buffer; $\mathrm{N}^{+}$, protonated amine concentration; $I_{c}$, ionic strength. All buffers

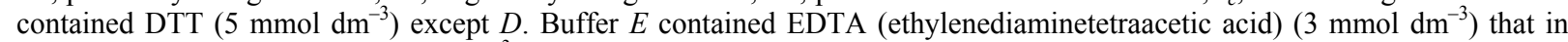
neutral solution exists mostly as $\mathrm{EDTA}^{3-}$ and Np40 (nonionic detergent, $\varphi=0.00005$ ). Buffer $I$ contained ATP (adenosine triphosphate) $\left(3 \mathrm{mmol} \mathrm{dm}^{-3}\right)$. In neutral solution, ATP is ionized and exists mostly as ATP ${ }^{4}$, with small proportion of ATP ${ }^{3-}$. All buffers contained Tris but $E$ and $H$ contained Hepes and this is denoted with subscript ${ }_{\mathrm{H}}$. $\mathrm{pH}$ of the buffers was 7.5 except for buffers $D$ and $H(\mathrm{pH}=8.0)$. Additional $\mathrm{Na}^{+}$and $\mathrm{Cl}^{-}$ions are due to corrections because of $\mathrm{pH}$ adjustment. $R_{\max }($ in $\mathrm{RU})$ is maximum binding of MtSerRS:tRNA ${ }^{\text {Ser }}$ in given conditions. 
The experimental curves were evaluated also in the state of equilibrium by Steady State Affinity model and average dissociation constant $K_{\mathrm{d}, \mathrm{av}}=186 \pm 19 \mathrm{nmol}$ $\mathrm{dm}^{-3}$ was defined (Figure $1 \mathrm{~b}$ ). The $K_{\mathrm{d}, \mathrm{av}}$ value is in good agreement with published data for the enzyme $\mathrm{mMbSerRS}^{13}$ and published $K_{\mathrm{d}}$ values for other synthetase:tRNA complexes involving CysRS, ${ }^{18}$ GlnRS, ${ }^{19,20}$ and AspRS. ${ }^{21}$

\section{Binding Responses Comparison of MtSerRS:tRNA ${ }^{\text {Ser }}$ Association in Qualitative Analysis by SPR}

To shed some light on the nature of binding between MtSerRS and tRNA ${ }^{\text {Ser }}$, the maximum binding capacity $R_{\max }$ (in RU) was measured using SPR in the presence of different concentration of salts and buffering components (Table 2). Analyte (tRNA ${ }^{\text {Ser }}$ ) was allowed to flow over immobilized ligand (MtSerRS). In all tested buffers the binding of tRNA was successful and reached measurable level of response. We compared the shape of the curves which were very informative without calculating individual rate constants in different reactions.
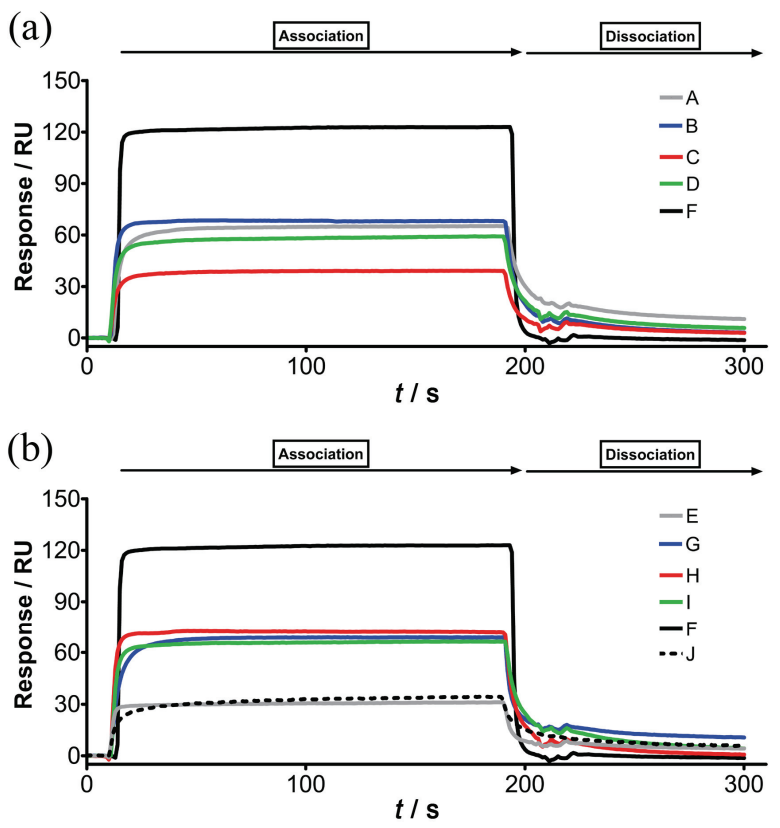

Figure 2. Binding responses comparison for binding between MtSerRS and tRNA ${ }^{\text {Ser }}\left(100 \mathrm{nmol} \mathrm{dm}^{-3}\right)$ in qualitative analysis by SPR. Overlay plots for SPR sensorgrams for interaction between tRNA ${ }^{\text {Ser }}$ and MtSerRS in reaction buffers $A, B, C, D$ and $F(\mathrm{a}) ; E, G, H, I, J$ and $F(\mathrm{~b})$ are shown. Association was allowed to proceed for 200 seconds at temperature of $20{ }^{\circ} \mathrm{C}$ with subsequent dissociation by injecting running buffer. All curves were corrected for bulk refractive index change and non-specific binding to the reference cell before estimating the binding kinetics. The buffer composition was defined in Experimental section and Table 2.
Interestingly, some curves for MtSerRS:tRNA ${ }^{\text {Ser }}$ complex formation did not achieve maximal response and are less steep indicating less efficient recognition of the substrate and slower association. Judging from the level of $R_{\max }$ the most favorable buffer for MtSerRS and tRNA $^{\text {Ser }}$ interaction was determined (buffer $F$, Figure 2). Figure 2 shows that the sensorgrams in reactions $E, F$ and $H$ climbed more sharply (increased slope) in the association phase that the other reaction sensorgrams indicating rapid association kinetics. When we used Hepes as a buffering chemical or omitted salt from buffer solution we observed decreased slope in the association phase of the sensorgram and low sensor response reaching only $25-30 \%$ of maximal response in optimal buffer $F$ (Figure 2 and Table 2).

In this line it is worth mentioning that efficient binding was observed only when using Tris as a buffering agent. Interaction is poor when Hepes is used as a buffering chemical even at high ionic strength (Figure 2, compare buffers $E, J$ and $F$ and Table 2). Examination of the chemical structures suggests that Hepes is less convenient buffer for MtSerRS:tRNA recognition. Hepes has a terminal sulfate group attenuating the protonated amine's attraction to tRNA phosphate and contains a positive charge within a central tertiary amine, which is less accessible than the primary amine in Tris. Therefore, amine substituents contribute to the binding of the enzyme and the tRNA and the binding is not strictly a function of ionic strength. Our results show that the composition of the buffer affects MtSerRS:tRNA ${ }^{\text {Ser }}$ binding as protonated amines can act as counterions to the tRNA phosphates. $^{22}$ This is seen in Table 2 where $R_{\max }$ is correlated with the concentration of the protonated amine.

Stability of the complex between yeast seryltRNA synthetase and tRNA ${ }^{\text {Ser }}$ under different electrophoretic conditions has been explored before ${ }^{23}$ and $K_{\mathrm{d}}$ values determined in the presence and absence of $\mathrm{Mg}^{2+}$ were essentially the same suggesting that $\mathrm{Mg}^{2+}$ ions mainly influence dissociation-association kinetics of the complex, with a minor contribution to its thermodynamic stability. ${ }^{23}$ Here we show in SPR that in the presence and in the absence of $\mathrm{Mg}^{2+}$ ions the binding response remains unchanged (buffer $F$ and $G$ lack magnesium chloride while buffer $B$ contains $6 \mathrm{mmol} \mathrm{dm}{ }^{-3} \mathrm{MgCl}_{2}$, Figure 2) and the shape of the curve suggests that magnesium ions did not influenced significantly neither the association nor the dissociation of the $\mathrm{tRNA}^{\mathrm{Ser}}$. In mMbSerRS structure ${ }^{11}$ the $\alpha$ - and $\beta$-phosphates of ATP coordinate a magnesium ion, which is bound to the side chains of Asp416, Glu432 and Asn435 but judging from this data the magnesium ions do not affect the binding of tRNA ${ }^{\text {Ser }}$ to MtSerRS. 
Table 3. Apparent dissociation constants $\left(K_{\mathrm{d}, \mathrm{app}}\right)$ for MtSerRS:tRNA ${ }^{\mathrm{Ser}}$ interaction determined at concentration $c\left(\mathrm{tRNA}^{\text {Ser }}\right)=$ $0.01 \mu \mathrm{mol} \mathrm{dm}{ }^{-3}$ in the presence of BSA or MtArgRS in gel mobility shift assay. $n$ is the Hill coefficient. The values are reported as arithmetic mean \pm standard error of mean (SEM)

\begin{tabular}{clcc}
\hline & & $K_{\text {d,app }} / \mu \mathrm{mol} \mathrm{dm}^{-3}$ & $n$ \\
\hline \multirow{2}{*}{${\text { MtSerRS }+ \text { tRNA }^{\text {Ser }}}^{*}$} & + BSA & $0.119 \pm 0.002$ & $2.7 \pm 0.3$ \\
& + MtArgRS & $0.062 \pm 0.001$ & $2.5 \pm 0.2$ \\
\hline
\end{tabular}

\section{Osmoadaptation of Thermophilic Methanogenic Archaea and Halotolerance of the Enzyme MtSerRS}

Archaea had to apply a wide range of strategies to survive in conditions of high salt concentration, e.g. sodium chloride. We have previously shown that MtSerRS catalyzed tRNA serylation in vitro suboptimally at low salt concentration. ${ }^{6}$ Only at salt concentrations above $100 \mathrm{mmol} \mathrm{dm}^{-3}$ the enzyme achieved satisfactory activity. This is in agreement with our current results revealing direct influence of sodium chloride concentration on the interaction between MtSerRS and tRNA ${ }^{\text {Ser }}$ (Figure 2, Table 2). There is a strong correlation between increased recognition of the tRNA ${ }^{\text {Ser }}$ and increasing ionic strength (Table 2 and Figure 2). As shown by $R_{\max }$ values (Table 2), the maximum binding capacity for SerRS:tRNA ${ }^{\text {Ser }}$ interaction was reached when elevating the concentration of sodium ions from $54 \mathrm{mmol} \mathrm{dm}^{-3}$ to $200 \mathrm{mmol} \mathrm{dm}^{-3}$ as well as using TrisHCl as a buffering component, consistent with the increasing number of positive charges of these cations (Table 2). Curve $H$ in Figure 2 shows higher response $\left(R_{\max }=72\right)$ then binding described with curves $C, E$ and $J$, and upon addition of more salt to the buffer, the response is increased to a maximal level (curve $F, R_{\max }=120$ ) (Figure 2), indicating a requirement of substantial quantities of $\mathrm{NaCl}$ for the interaction. Curves $A, B, D$ and $I$ show a reduced interaction potential due to decreased concentration of salt (Figure 2). Interestingly, curves $C, A, J$ and $\mathrm{G}$ (Figure 2) show less steep curve in the association part of the curve compared to curve $F$ indicating slower association. From ranking experiment (Figure 2) it is evident that $c(\mathrm{NaCl}) \geq 100 \mathrm{mmol} \mathrm{dm}^{-3}$ should be present in reaction for optimal recognition between MtSerRS and tRNA ${ }^{\text {Ser }}$. These findings strengthen the conclusion that association of MtSerRS and tRNA ${ }^{\text {Ser }}$ is actually stabilized by elevated ionic strength. These findings are reminiscent of the aminoacylation assays conducted in the presence of $250 \mathrm{mM} \mathrm{KCl}$ for LysRS, LeuRS and ProRS from M. thermautotrophicus. ${ }^{24}$ In contrast, the standard aminoacylation reactions by bacterial and eukaryotic SerRSs are usually carried out without salt. $^{25}$ Thus, salt-dependent association between MtSerRS and tRNA ${ }^{\text {Ser }}$ may provide one of the mechanisms of osmoadaptation of methanogenic archaea. Unlike bacteria, most archaea require high concentration of cations $\left(e . g . \mathrm{K}^{+}\right)$in the cell for optimal growth conditions. ${ }^{26} M$. thermautotrophicus (strain $\Delta \mathrm{H}$ ) grows very well at the concentrations of sodium chloride up to $0.60 \mathrm{~mol} \mathrm{dm}^{-3}$. Moreover, the intracellular concentration of potassium ions ${ }^{27}$ in $M$. thermautotrophicus is high as 0.65 to $1.1 \mathrm{~mol} \mathrm{dm}^{-3}$. In this respect, the organisms can adapt and evolve proteins that can function at higher salt concentrations. Comparison of the total amino acid content of ribosomal proteins revealed $29 \%$ of acidic ribosomal proteins in $M$. thermautotrophicus compared to only $7 \%$ in $E$. coli while halofils contain over $50 \%$ of acidic ribosomal proteins. Moreover, these proteins are less hydrophobic and the effect of salting out with cations is decreased. Therefore, cations can stabilize proper folding of proteins that can function at harsh ionic conditions.

\section{Alteration of $K_{d}$ Value in MtSerRS:tRNA ${ }^{\text {Ser }}$ Associa- tion Upon Addition of MtArgRS}

The effect of MtArgRS on the tRNA ${ }^{\text {Ser }}$ binding by MtSerRS was investigated in vitro by gel mobility shift assay. Quantification of free and bound RNA bands in gel mobility shift assay allowed the binding curve for MtSerRS:tRNA ${ }^{\text {Ser }}$ to be analyzed (Figure 3). Saturation binding was displayed graphically, and a sigmoidal curve was obtained as shown in Figure $3 \mathrm{a}$, indicating cooperative binding, and could not be fit to the standard single-site binding model. In SPR, a sensorgram of a heterogeneous analyte binding to immobilized ligand (Figure 1) represents the sum of two separate binding interactions. If second tRNA has a higher binding affinity than the first tRNA, the gel-shift data will reflect the binding kinetics of the higher affinity tRNA. If $K_{\mathrm{a} 2}$ is very large compared to $K_{\mathrm{a} 1}$ then the major species present in solution are either $[\mathrm{B}]$ or $\left[\mathrm{A}_{2} \mathrm{~B}\right]$ (see Experimental) and from gel-shift analysis the apparent dissociation constant $K_{\text {d,app }}$ of $119 \mathrm{nmol} \mathrm{dm}{ }^{-3}$ was obtained for both binding steps occurring at the same time. Interestingly, when MtArgRS was added in the reaction, the $K_{\text {d,app }}$ for tRNA ${ }^{\text {Ser }}$ was decreased two-fold to $62.0 \mathrm{nmol}$ $\mathrm{dm}^{-3}$ (Table 3). This finding is in agreement with previous kinetic experiments ${ }^{6}$ where $K_{\mathrm{m}}$ for tRNA ${ }^{\text {Ser }}$ was reduced also two-fold in the presence of MtArgRS. Interaction between MtSerRS and MtArgRS enhanced tRNA $^{\text {Ser }}$ aminoacylation, in agreement with previous reports of improved aminoacylation upon aaRS complex formation in archaea and yeast. ${ }^{4-6,24,28}$ While the details 

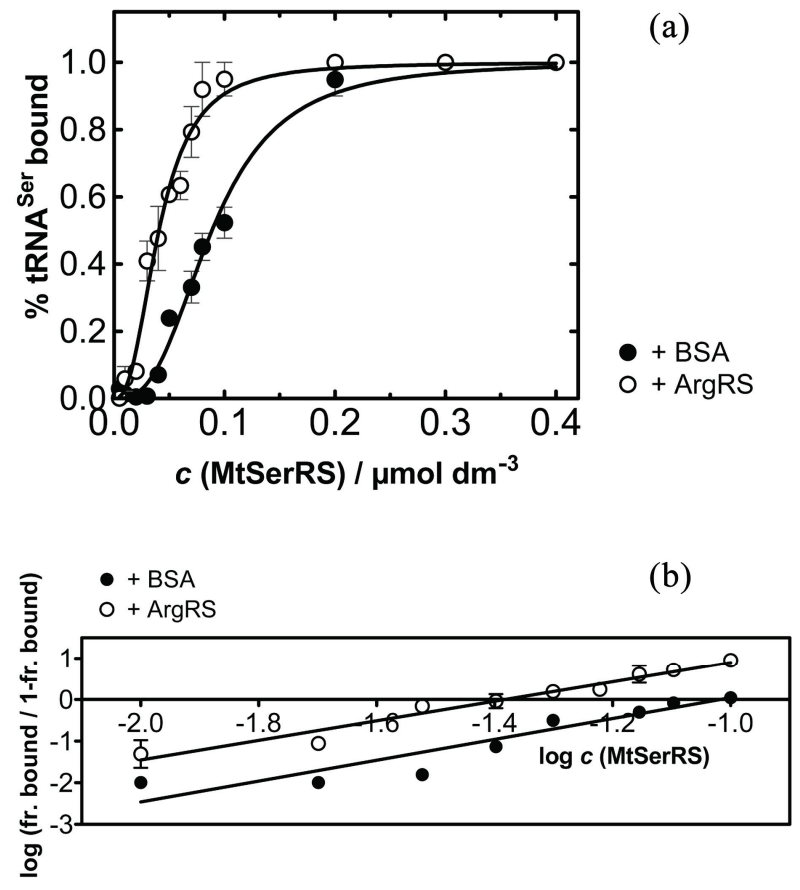

Figure 3. Binding of MtSerRS to tRNA ${ }^{\text {Ser }}$ in gel mobility shift assay. Saturation binding curve for interaction of MtSerRS and $\operatorname{tRNA}^{\text {Ser }}\left(0.01 \mu \mathrm{mol} \mathrm{dm}{ }^{-3}\right)$ in the presence of BSA $(\bullet)$ or MtArgRS ( $\circ$ ). Dissociation equilibrium constants were determined in gel mobility shift assay. Data obtained were analyzed by ImageQuant software and then used to plot the saturation binding curve as shown (a). Hill plot of the experimental data obtained from the binding assay (panel (a)) (b). Hill coefficients of 2.7 and 2.5 were obtained in the absence and the presence of the MtArgRS, respectively. The assay conditions

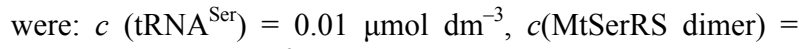
$0.005-0.4 \mu \mathrm{mol} \mathrm{dm}{ }^{-3}, c($ GST-MtArgRS $)=0.005-0.4 \mu \mathrm{mol}$

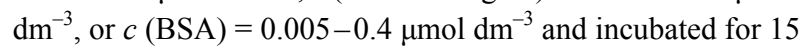
min at temperature of $37^{\circ} \mathrm{C}$ in $20 \mathrm{mmol} \mathrm{dm}{ }^{-3} \mathrm{TrisHCl}(\mathrm{pH}=$ 7.0), $50 \mathrm{mmol} \mathrm{dm}{ }^{-3} \mathrm{NaCl}$ and $6 \mathrm{mmol} \mathrm{dm}{ }^{-3} \mathrm{MgCl}_{2}$. The experiment was designed to run at a concentration of tRNA which is much lower than the dissociation constant of the MtSerRS:tRNA ${ }^{\text {Ser }}$. The values are reported as arithmetic mean \pm standard error of mean (SEM).

of this interaction remain to be resolved, our data indicate that the presence of MtArgRS in this macromolecular assembly could improve the efficiency of the translational machinery by facilitating the recognition of the tRNA $^{\text {Ser }}$ by MtSerRS as shown in this work (Table 3).

When the saturation-binding data from Figure $3 \mathrm{a}$ was fit to the Hill equation (Figure $3 b$ ) the Hill coefficients in the absence and the presence of the MtArgRS were calculated (Table 3 ). The observed cooperativity for binding of tRNA ${ }^{\text {Ser }}$ to SerRS (Figure 3a) is also reflected in the Hill coefficient, which for MtSerRS:tRNA ${ }^{\text {Ser }}$ (Table 3) was $2.7 \pm 0.3$, and $2.5 \pm 0.2$ when challenged with BSA or MtArgRS, respectively (Figure 3b). The (a)
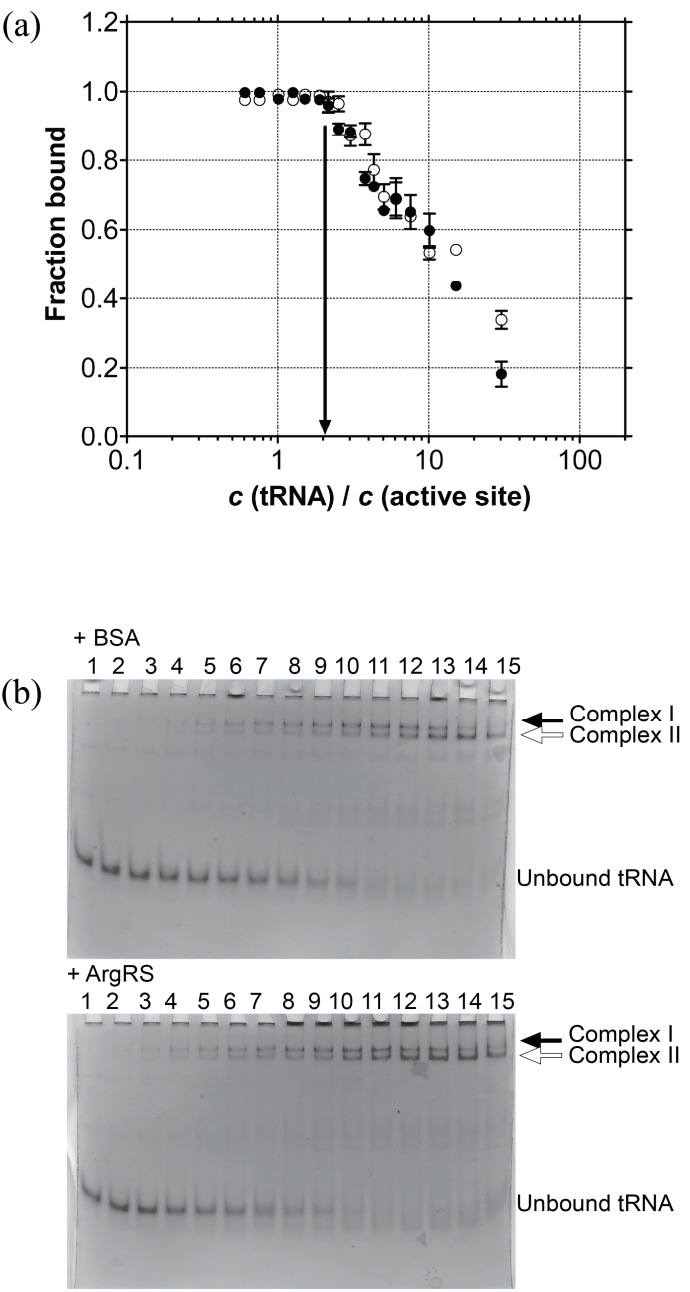

Figure 4. Stoichiometric titration of the MtSerRS:tRNA ${ }^{\text {Ser }}$ complex. Stoichiometric binding of MtSerRS to tRNA ${ }^{\text {Ser }}$ containing BSA (०) or GST-MtArgRS (•) (a). The gel mobility shift assays were performed as in panel (b). For each protein concentration, fractional saturation was calculated for three trials and quantified using ImageQuant software. Representative gel of MtSerRS:tRNA ${ }^{\text {Ser }}$ complexes stained with Toluidine blue (b). Note the bands of fully shifted (top) and unbound (bottom) tRNA bands. tRNA ${ }^{\text {Ser }}\left(1.0 \mu \mathrm{mol} \mathrm{dm}{ }^{-3}\right)$ was titrated with increasing concentrations of proteins $(c$ (MtSerRS dimer $\left.)=0.06-1.32 \mu \mathrm{mol} \mathrm{dm}{ }^{-3}\right)($ wells $2-15)$. Complex $I$ is marked with black arrow and complex $I I$ with the white arrow.

observed Hill coefficients in both cases suggest that two molecules of tRNA ${ }^{\text {Ser }}$ bind to MtSerRS.

\section{MtSerRS Forms Two Kinds of Complexes with tRNA $^{\text {Ser }}$}

Evidence to support a two tRNA-binding site model (Figure 1) is provided by gel mobility shift assay (Figure 4) where interaction of MtSerRS with tRNA ${ }^{\text {Ser }}$ leads to appearance of two bands representing two kind of complexes, probably MtSerRS:(tRNA $\left.{ }^{\mathrm{Ser}}\right)_{1}$ and MtSerRS:(tRNA $\left.{ }^{\mathrm{Ser}}\right)_{2}$. 
The binding stoichiometry of MtSerRS:tRNA ${ }^{\text {Ser }}$ complex was determined from the amount of protein required to saturate binding to a fixed concentration of tRNA $^{\text {Ser }}$ (Figure 4a). The concentration of the fixed component was 50 -fold greater than the $K_{\mathrm{d}}$ to permit direct stoichiometric titration. In the presence of BSA, we find that protein dimer fully binds to tRNA ${ }^{\text {Ser }}$ present in the reaction at concentration of $0.275 \mu \mathrm{mol} \mathrm{dm}{ }^{-3}$ (protein dimer:tRNA ratio 0.55 ), while in the presence of GST-MtArgRS, full binding of protein dimer to tRNA $^{\text {Ser }}$ was achieved at concentration of $0.205 \mu \mathrm{mol}$ $\mathrm{dm}^{-3}$ (protein dimer:tRNA ratio 0.41) in agreement with binding stoichometry of 2 RNA molecules per protein dimer.

Seryl-tRNA synthetases from Thermus thermophilus and Escherichia coli form two types of noncovalent complexes with tRNA ${ }^{\text {Ser; }}$ SerRS:(tRNA $\left.{ }^{\text {Ser }}\right)_{1}$ and SerRS:(tRNA $\left.{ }^{\mathrm{Ser}}\right)_{2}{ }^{29-31}$ The tRNA is bound across the two subunits of dimeric SerRS, as revealed by the SerRS:(tRNA $\left.{ }^{\text {Ser }}\right)_{1}$ crystal structure ${ }^{11,30}$ and biochemical studies on heterodimers. ${ }^{12,32}$ SerRS from the yeast $\mathrm{Sac}$ charomyces cerevisiae has also been found to bind one or two tRNA ${ }^{\text {Ser }}$ cooperatively ${ }^{24}$. Measurements of affinity (Figure 3), stoichiometry (Figure 4) and cooperativity (Table 3) suggest that communication among subunits in MtSerRS dimer is required for tRNA ${ }^{\text {Ser }}$ binding. We favor the model of two tRNA ${ }^{\text {Ser }}$ molecules bound per MtSerRS protein dimer in cooperative manner. It can be speculated that binding of one molecule facilitates binding of the other tRNA molecule to MtSerRS as supported by gel-shift experiment (Figure 4b). To explore these possibilities in future crystallographic experiments will be an intriguing task.

Overall SerRS structure is very flexible. Docking model of mMbSerRS:tRNA complex ${ }^{12}$ implies that the $\mathrm{N}$-terminal domain of one protomer in the dimer will bind the variable arm of the tRNA ${ }^{\text {Ser }}$, whereas the 3 '-end of the same tRNA will enter the active site of the other protomer. ${ }^{12}$ Catalytic and N-terminal domains of SerRS have to act synergistically to provide a high and specific binding affinity for their cognate tRNA ${ }^{\text {Ser }} .^{12}$ Although tRNA-binding domains in the two SerRS types are non-homologous and evolutionarily unrelated, ${ }^{11}$ the requirement for a closing movement of the N-terminal domain upon tRNA binding has been observed in the T. Thermophilus SerRS:tRNA co-crystal structure ${ }^{33}$ and predicted by docking model. ${ }^{11}$ The initial capture of the tRNA is likely to be facilitated by the flexible disposition of the N-terminal domain, which will then deliver the tRNA to the active site of the enzyme via a hingelike motion mediated by HTH interactions. ${ }^{12}$ Unlike some synthetases such as aspartyl-tRNA synthetase, where each monomer interacts with only one tRNA molecule, here each tRNA ${ }^{\text {Ser }}$ binds both monomers of
SerRS (cross-dimer binding) ${ }^{12}$ and it is tempting to further explore tRNA-induced cooperative effects. Crossubunit interactions with the tRNA have also been identified in ProRS and ThrRS. ${ }^{34}$ In ThrRS, the binding of tRNA by one monomer, by breaking a salt bridge, presumably modifies the position and flexibility of the ordering loop of the other monomer and consequently affects the binding or release of the substrates in the second active site. ${ }^{34}$ This type of tRNA-induced intersubunit communication needs to be further explored in serine system because it could constitute another functional link between members of subclass IIa.

\section{CONCLUSION}

The kinetic parameters for binding MtSerRS and tRNA $^{\text {Ser }}$ were determined using surface plasmon resonance (Figure $1 \mathrm{~b}$ and Table 1) in agreement with the Heterogeneous analyte binding model. Results show that the affinity of tRNA ${ }^{\text {Ser }}$ for the second binding site is approximately 10 -fold stronger compared to affinity for the first binding site $\left(K_{\mathrm{d} 1}=1.455 \mu \mathrm{mol} \mathrm{dm}{ }^{-3}, K_{\mathrm{d} 2}=\right.$ $0.1459 \mu \mathrm{mol} \mathrm{dm}{ }^{-3}$, Table 1).

The analysis of the binding data from three separate experiments revealed presence of positive cooperativity in formation of the MtSerRS:tRNA ${ }^{\text {Ser }}$ binding complexes (Figure 3a) displayed as sigmoidal saturation curve.

There is a correlation between efficiency of binding $\left(R_{\max }\right)$ tRNA $^{\text {Ser }}$ to MtSerRS and elevated ionic strength that was observed only when using Tris rather than Hepes as a buffering chemical. By comparison of the binding responses and shape of sensorgrams we show that magnesium ions do not affect the binding of tRNA $^{\text {Ser }}$ to MtSerRS.

Further evidence to support a two tRNA-binding site model (Figure 1) was provided by gel mobility shift assay (Figure 4) where interaction of MtSerRS with tRNA $^{\text {Ser }}$ leads to appearance of two bands representing two kind of complexes, probably MtSerRS:(tRNA $\left.{ }^{\text {Ser }}\right)_{1}$ and MtSerRS:(tRNA $\left.{ }^{\text {Ser }}\right)_{2}$.

MtSerRS:tRNA ${ }^{\text {Ser }}$ complex formation was stimulated by the addition of MtArgRS, which is an interacting partner of MtSerRS. The presence of MtArgRS led to a two-fold decrease in $K_{\text {d,app }}$ for MtSerRS:tRNA ${ }^{\text {Ser }}$ (Table 3), but had no affect on cooperative properties or stoichiometry of the complex (Figure 4).

While the details of this interaction remain to be resolved, our data indicate that the complex formation between MtArgRS and MtSerRS may improve the efficiency of the translational machinery, assuring more efficient recognition of the $\mathrm{tRNA}^{\mathrm{Ser}}$ by MtSerRS as presented in this work (Table 3 ). 
Acknowledgements. This work was supported by the grant from the Ministry of Science, Education and Sports of Republic of Croatia (project 119-0982913-1358). Stefan Schauer from the Functional Genomics Center Zürich is acknowledged for assistance in SPR experiments.

\section{REFERENCES}

1. S. H. Zaher and R. Green, Cell 136 (2009) 746-762.

2. J. Ling, N. Reynolds, and M. Ibba, Annu. Rev. Microbiol. 63 (2009) 61-78.

3. M. Ibba and D. Söll, Annu. Rev. Biochem. 62 (2000) 617-650.

4. S. G. Park, K. L. Ewalt, and S. Kim, TRENDS in Biochem. Sci. 30 (2005), 569-574.

5. C. D. Hausmann and M. Ibba, FEMS Microbiol. Rev. 32 (2008) $705-721$.

6. V. Godinić-Mikulčić, J. Jarić, C. D. Hausmann, M. Ibba, and I. Weygand-Đurašević, J. Biol. Chem. 286 (2011) 3396-3404.

7. D. Tumbula, U. C. Vothknecht, H. S. Kim, M. Ibba, B. Min, T. Li, J. Pelaschier, C. Stathopoulos, H. Becker, and D. Söll, Genetics 152 (1999) 1269-1276.

8. H. S. Kim, U. C. Vothknecht, R. Hedderich, I. Celic, and D. Söll, J. Bacteriol. 180 (1998) 6446-6449.

9. D. Korencic, I. Ahel, and D. Soll, Food Technol. Biotechnol. 40 (2002) 235-260

10. S. Bilokapić, N. Ban, and I. Weygand-Đurašević, Croat. Chem. Acta 82 (2009) 493-501.

11. S. Bilokapić, T. Maier, D. Ahel, I. Gruić-Sovulj, D. Söll, I. Weygand-Đurašević, and N. Ban, EMBO J. 25 (2006) 2498-2509.

12. S. Bilokapić, N. Ivić, V. Godinić-Mikulčić, I. Piantanida, N. Ban, and I. Weygand-Đurašević, J. Biol. Chem. 284 (2009) 10706-10713.

13. J. Jarić, S. Bilokapić, S. Lesjak, A. Crnković, N. Ban, and I. Weygand-Đurašević, J. Biol. Chem. 284 (2009) 30643-30651.

14. I. Weygand-Đurašević and S. Cusack, Seryl-tRNA Synthetases in: M. Ibba, C. Francklyn, S. Cusack (Eds.), The AminoacyltRNA Synthetases. Landes Biosciences, Georgetown (SAD), 2005, pp. 177-192.

15. V. Biou, A. Yaremchuk, M. Tukalo, and S. Cusack, Science 263 (1994) 1404-1410.
16. V. Godinić, M. Močibob, S. Ročak, M. Ibba, and I. WeygandĐurašević, FEBS J. 274 (2007) 2788-2799.

17. D. Korenčić, C. Polycarpo, I. Weygand-Đurašević, and D. Söll, J. Biol. Chem. 279 (2004) 48780-48786.

18. C. M. Zhang, J. J. Perona, and Y. M. Hou, Biochemistry 42 (2003), 10931-10937.

19. I. Weygand-Đurašević, E. Schwob, and D. Söll, Proc. Natl. Acad. Sci. U. S. A. 90 (1993) 2010-2014.

20. T. L. Bullock, L. D. Sherlin, and J. J. Perona, Nat. Struct. Biol. 7 (2000) 497-504.

21. M. Frugier, L. Moulinier, and R. Giegé, EMBO J. 19 (2000) 2371-2380.

22. J. R. Wenner and V. A. Bloomfield, Anal. Biochem. 268 (1999) 201-212.

23. I. Gruić-Sovulj, J. Rokov-Plavec, M. Močibob, T. Kamenski, and I. Weygand-Đurašević, Croat. Chem. Acta 77 (2004) 599-604.

24. M. Praetorius-Ibba, C. D. Hausmann, M. Paras, T. E. Rogers, and M. Ibba, J. Biol. Chem. 282 (2007) 3680-3687.

25. C. S. Francklyn, E. A. First, J. J. Perona and Y. M. Hou, Methods 44 (2008) 100-118.

26. R. Ciulla, C. Clougherty, N. Belay, S. Krishnan, C. Zhou, D. Byrd, and M. F. Roberts, J. Bacteriol. 176 (1994) 3177-3187.

27. D. D. Martin, R. A. Ciulla, and M. F. Roberts, Appl. Environ. Microbiol. 65 (1999) 1815-1825.

28. G. Simos, A. Sauer, F. Fasiolo, and E. C. Hurt, Mol. Cell. 1 (1998) 235-242.

29. F. Borel, C. Vincent, R. Leberman, and M. Härtlein, Nucleic Acids Res. 22 (1994) 2963-2969.

30. A. D. Yaremchuk, M. A. Tukalo, I. Krikliviy, N. Malchenko, V. Biou, C. Berthet-Colominas, and S. Cusack, FEBS Lett. 310 (1992) 157-161.

31. S. Price, S. Cusack, F. Borel, C. Berthet-Colominas, and R. Leberman, FEBS Lett. 324 (1993) 167-170.

32. C. Vincent, F. Borel, J. C. Willison, R. Leberman, and M. Härtlein, Nucleic Acids Res. 23 (1995) 1113-1118.

33. S. Cusack, A. Yaremchuk, and M. Tukalo, EMBO J. 15 (1996) 2834-2842.

34. A. Torres-Larios, R. Sankaranarayanan, B. Rees, A.-C. DockBregeon, and Dino Moras, J. Mol. Biol. 331 (2002) 201-211.

35. A. Chenal, P. Nizard, V. Forge, M. Pugniere, M. O. Roy, J. C. Mani, F. Guillain, and D. Gillet, Protein Eng. 15 (2002) 383-391.

36. K. J. Ellis and J. F. Morrison, Methods Enzymol. 182 (1982) 24-38. 